\title{
POLITIK IDENTITAS MASYARAKAT PERBATASAN INDONESIA-MALAYSIA: KASUS BADAU DI KAPUAS HULU, KALIMANTAN BARAT
}

\author{
Irwan Abdullah dan Intan Pemata Sari \\ Fakultas Ilmu Budaya, Universitas Gadjah Mada \\ Email:irwanabdullah6@gmail.com
}

\begin{abstract}
Border area studies has become extremely important since the state border creates tensions of sovereignty and identity in relations between Indonesia and ten other neighboring countries. Border area cannot perceive as only a neutral area without any meanings as it becomes a mirror of the nation since it is the entrance for the coming of people and goods from other countries. The border area therefore is not only a statement of the administrative line of the country that is influential for the sovereignty, but also of the cultural line to stress identity. This article shows that administrative-political border which divides Dayak Iban become two parts has also created the tension between state-society in the border area, as the nationalism has to face the distressed ethnic identities. Dual existence of the ethnic group is influential on the maintenance of identity and nationalism of the border community, which shows a challenge to the role of the state. Moreover, the living condition of Dayak Iban in Badau is in contrast to the Dayak Iban in Lubok Antu, which is more prosperous. The fact that the people in the border area live in scarcity, adversity, and inadequate has delegitimated the state existence that challenges the national identity. The situation has produced the fact that people of Badau perform three identities: as a border society (politics), as part of the Iban community (cultural), and as part of global society (economy). The findings sharpen Foote and Burke's theory by presenting that identity is not only determined by the structural relations, but also developed through contested process where the actors also produce meanings to state their existence.
\end{abstract}

Keywords: Border Studies, Cultural Identity, Identity Politics, and West Borneo.

\begin{abstract}
ABSTRAK
Studi wilayah perbatasan menjadi sangat penting sejak batas Negara melahirkan ketegangan kedaulatan dan identitas dalam hubungan Indonesia dengan sepuluh Negara tetangga. Wilayah perbatasan tidak dapat dipandang sebagai wilayah netral tanpa makna karena menjadi cermin suatu bangsa akibat keberadaannya sebagai pintu gerbang masuknya orang dan barang dari Negara lain. Wilayah perbatasan karenanya bukan saja sebagai pernyataan batas administratif negara yang berpengaruh terhadap kedaulatan suatu Negara, tetapi juga batas kultural yang menegaskan identitas bangsa. Tulisan ini memperlihatkan bahwa batas administrative-politis yang membelah etnis Dayak Iban menjadi dua bagian telah pula melahirkan ketegangan hubungan Negara-rakyat di perbatasan karena tuntutan nasionalisme berhadapan langsung dengan identitas etnis yang telah terganggu.Keberadaan etnis yang mendua telah berpengaruh pada pemeliharaan identitas dan nasionalisme masyarakat perbatasan yang memperlihatkan suatu gugatan terhadap peran negara.Apalagi, kehidupan Dayak Iban di Badau bertolak belakang dengan Dayak Iban di Lubok Antu Serawak yang lebih sejahtera. Kenyataan bahwa penduduk di perbatasan hidup dalam kekurangan, kesulitan, keterbatasan telah menyebabkan terjadinya delegitimasi Negara yang mengancam identitas nasional. Keadaan ini telah
\end{abstract}


menyebabkan masyarakat Badau memiliki tiga identitas, yaitu identitas sebagai masyarakat perbatasan (politik), identitas sebagai bagian dari masyarakat Iban (kultural), dan identitas sebagai bagian dari masyarakat global (ekonomi). Temuan ini mempertajam teori Foote dan Burke dengan memperlihatkan bahwa selain ditentukan oleh hubungan-hubungan struktural, suatu identitas juga dibangun melalui proses kontestatif yang memperlihatkan bahwa aktor juga memproduksi makna dalam menegaskan keberadaannya.

Kata Kunci: Studi Perbatasan, Identitas kultural, Politik Identitas, Kalimantan Barat

\section{PENGANTAR}

Pembicaraan mengenai wilayah perbatasan tidak dapat dipisahkan dari kesan terisolir, terbatas, dan jauh dari perhatian pemerintah.Kesan ini tidak dapat disalahkan karena demikianlah adanya di hampir seluruh wilayah perbatasan Indonesia. Kondisi memperhatinkan ini disebabkan oleh kesalahan paradigma yang dibangun secara akademis dan praktis yang menganggap bahwa wilayah perbatasan berada di pedalaman atau pinggiran yang sekaligus diposisikan di belakang atau terbelakang sehingga kurang penting diperjuangkan dalam perspektif yang bias modernisme. Dengan cara ini wilayah perbatasan gagal diposisikan sebagai wajah Negara yang langsung dilihat oleh pihak lain yang sekaligus menjadi gerbang depan masuknya bangsa asing ke wilayah Indonesia. Wilayah perbatasan karena, bukanlah sekadar pembatas atau pemisah satu Negara, namun lebih merupakan garis terdepan dari tandatanda kedaulatan dan peradaban sebuah bangsa.

Salah paham dan keliru pandang atas wilayah perbatasan ini telah menciptakan keterasingan yang kemudian terlupakan dalam perumusan kebijakan dan hitunghitungan anggaran. Akibatnya, Negara tidak hadir dan tangan-tangan Negara tidak cukup panjang untuk menyelesaikan persoalan yang kompleks (Abdullah, 2010; Tirtosudarmo, 2005). Masyarakat wilayah perbatasan pun semakin terbiasa menyelesaikan masalah mereka sendiri, sebisa yang mereka mampu, memenuhi kebutuhan-kebutuhan dasar.
Pada saat yang sama pembentukan identitas masyarakat pun berlangsung secara kontestatif untuk mendefinisikan siapa mereka: di satu sisi mereka menjadi bagian dari suatu entitas general bangsa Indonesia dan di sisi lain terabaikan secara sosial dan material.

Persoalan kontestasi identitas ini akan dibicarakan dengan mengacu pada kasus Badau, suatu wilayah perbatasan di Kapuas Hulu, Kalimantan Barat. Daerah Badau berbatasan langsung dengan Lubok Anto, suatu wilayah di Serawak, Malaysia. Baik penduduk Badau maupun Lubok Anto berasal dari suku yang sama, yakni Dayak Iban, yang karenanya menciptakan kesulitan tersendiridalam definisi identitas. Batas-batas Negara, yang telah dilihat sebagai pemisah, telah membelah satu kebudayaan menjadi dua bagian yang kemudian melahirkan identitas ganda di kalangan Dayak Iban. Latar belakang sejarah dan kultural mereka yang sama dipisahkan oleh garis politik yang tegas dan dengan garis hukum yang tajam yang dengan mudah melukai emosi kultural Dayak Iban.

Studi identitas memiliki akar sejarah yang panjang pada pendekatan interaksionalisme simbolik yang didasarkan pada pemikir-pemikir awal (Foote, 1951; Stryker, 1987).Pada saat itu diyakini bahwa suatu fenomena bisa dipahami melalui definisi dan interpretasi atas makna-makna yang diberikan aktor pada lingkungannya. Perspektif masyarakat dalam melihat dunia dan alasan mengapa mereka melakukan sesuatu dengan cara mereka sendiri dapat dipahami, khususnya menyangkut cara-cara suatu masyarakat membangun identitas (Meltzer et al., 1997). Nelson Foote (1951) sebagai tokoh yang pertama menggunakan istilah identitas telah mencoba untuk memberikan pengayaan atas pemahaman konseptual ketika ia mengatakan bahwa tujuan-tujuan telah menentukan bagaimana seseorang melakukan sesuatu. Keberadaan individu tidak bisa dilepaskan dari struktur yang turut mendefinisikan identitasnya yang memberi kerangka atas simbol-simbol yang membedakan satu dengan yang lain. 
Pentingnya struktur ini ditegaskan oleh Burke ketika ia mengatakan bahwa identitas diri manusia tidak bisa dipandang sebatas siapa dia, tetapi identitas dirihanya bisa dijelaskan melalui relasi-relasi sosial yang berada di sekitar "aktor", yang dengan relasi sosial ini pada akhirnya terbentuk struktur sosial yang berlaku dalam masyarakat. Sejalan dengan ini dikatakan bahwa identitas merupakan: "...the character and the role that an individual devises for himself as an occupant of a particular social position" (McCall and Simmons, 1978: 65). Hal serupa dikatakan Stone (1962: 93), yang menurutnya: “...a person's identity is established when others place him the same words of identity that he appropriate to himself." Dengan demikian, keberadaan seorang individu tidak dapat dilepaskan dari suatu struktur yang turut mendefinisikan identitasnya. Demikian pula proses identifikasi berlangsung dalam suatu struktur yang memiliki serangkaian nilai dan persyaratan yang harus dipenuhi walaupun seorang individu dapat melakukan tawar menawar dalam hubungannya dengan struktur di mana ia menjadi bagian, seperti daerah perbatasan yang melibatkan berbagai aktor yang turut mendefinisikan identitas individu atau kelompok.

Tulisan ini tidak dapat melepaskan hubungan struktur dengan kultur etnis dalam proses konstruksi identitas yang bersifat kontestatif yang melibatkan dua Negara dan aktor-aktor swasta. Etnis Dayak Iban di satu sisi memiliki definisi dan interpretasi tentang dirinya atas dasar geneologi etnis dan kultur etnis, tetapi mereka hidup dalam struktur Negara yang memiliki sistem politik yang mengatur keberadaan mereka bukan sebagai suatu suku tetapi sebagai warga dari dua Negara bangsa: Indonesia dan Malaysia.

\section{PEMBAHASAN \\ Badau di Perbatasan Indonesia- Malaysia}

Kecamatan Badau berbatasan langsung dengan Distrik Lubok Antu, Sriaman, Negari Sarawak, Malaysia. Kecamatan Badau yang beribukota Nanga Badau memiliki luas wilayah kurang lebih 700 $\mathrm{km}^{2}$ yang meliputi 2,35\% dari seluruh wilayah Kabupaten Kapuas Hulu (Gambar 1) Jarak antara Kecamatan Badau dengan ibukota Kabupaten, Putussibau, sejauh $177 \mathrm{~km}$ dengan infrastruktur yang masih buruk.Badau ini merupakan salah satu titik perbatasan wilayah Negara dari lima titik perbatasan di Kalimantan Barat yang ditandai dengan adanya Pos Lintas Batas (PLB), yakni PLB Entikong, Jagoi Babang, Senaning, Sajingan, dan Badau (Prasojo, 2013). Jika wilayah perbatasan dipahami sebagai titik perbatasan, maka lima titik tidaklah memadai untuk menjaga kedaulatan Negara apalagi dengan fasilitas yang masih terbatas (Lihat Gambar 2) PLB Badau, misalnya, sudah rusak sebelum diresmikan pada tahun 2012 akibat terlalu lama dibiarkan dan tidak difungsikan hampir sepuluh tahun menunggu kesiapan sarana prasarana dan SDM dalam pembentukan PLB Badau. 


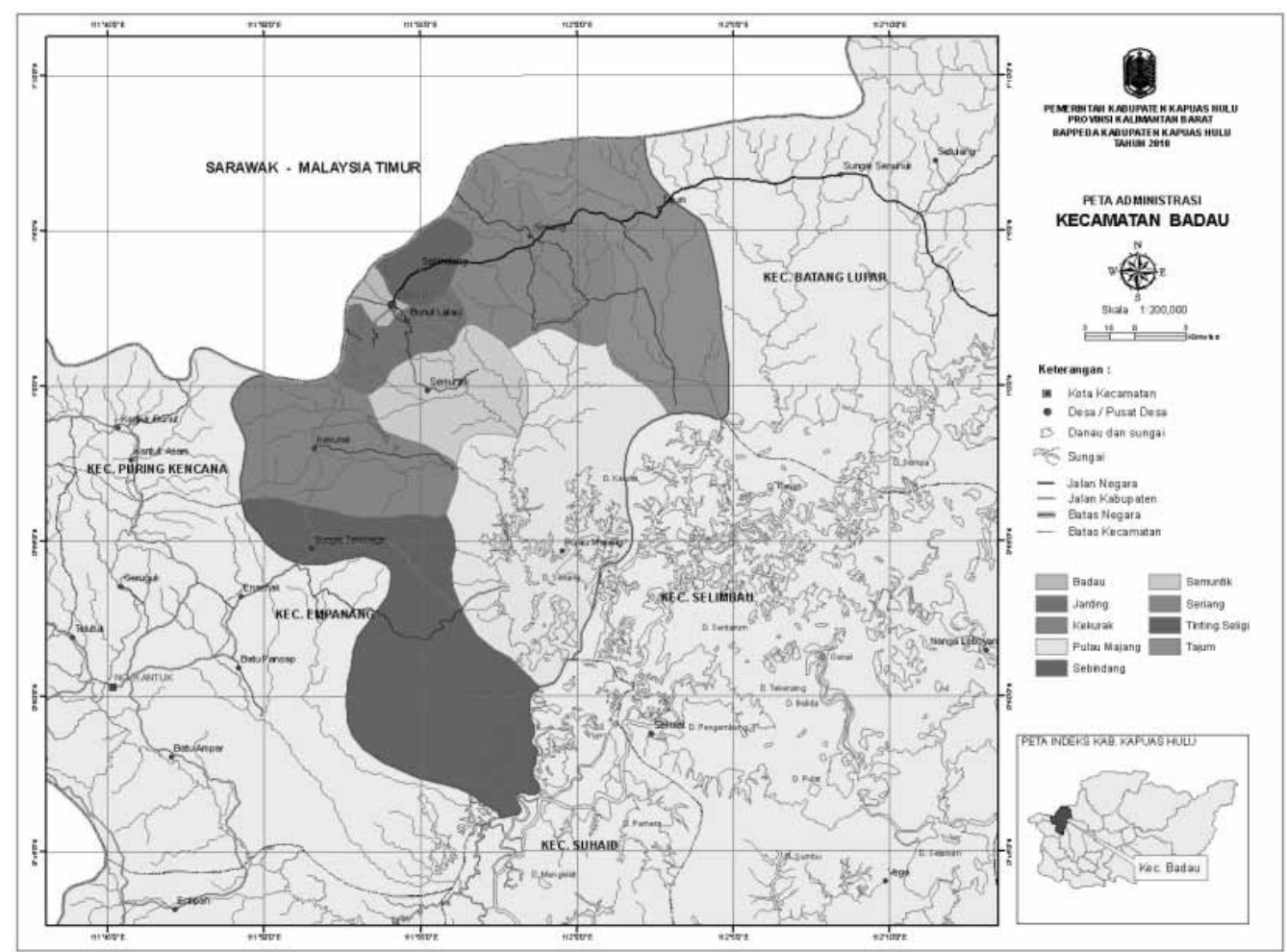

Gambar 1: Peta Kecamatan Badau, Kapuas Hulu, Kalimantan Barat

Sumber: www.google.com

Dari aspek garis, wilayah Kapuas Hulu memiliki garis sepanjang $300 \mathrm{~km}$ dari seluruh garis perbatasan Kalimantan Barat yang panjangnya kurang lebih $960 \mathrm{~km}$. Garis batas yang panjang ini sangat sulit untuk dijaga, apalagi letak garis batas wilayah Badau dengan Malaysia masih rancu. Walaupun sudah banyak tapal batas yang ditanam bersama-sama oleh polisi Indonesia dan Malaysia yang disaksikan oleh warga, tapal batas itu masih menjadi perdebatan. Selain itu, masih banyak wilayah yang belum diberikan batas secara resmi karena panjangnya garis batas dan banyaknya tapal batas yang berpindah tempat atau bahkan hilang.Walaupun penjagaan telah dilakukan oleh TNI, jumlah personil negara untuk menjaga tapal batas masih sangat terbatas.

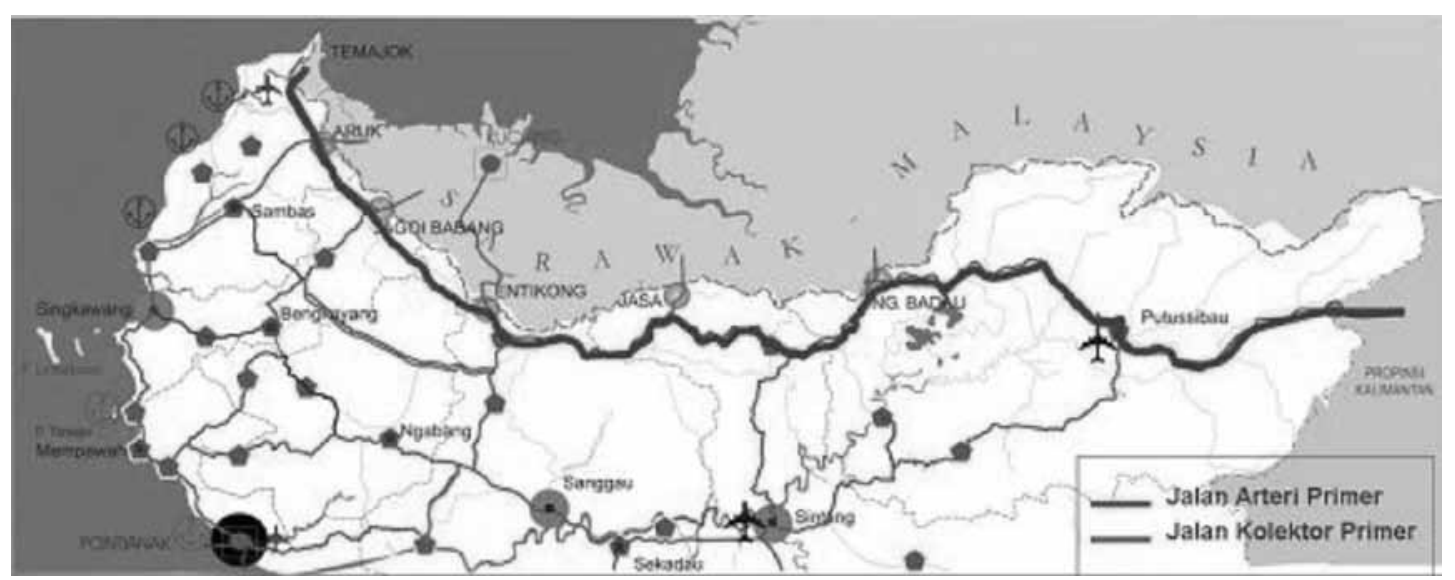

Gambar 2: Lima Titik Pos Lintas Batas di Kalimantan Barat Sumber: www.google.com 
Sebagai bagian dari serambi depan wilayah Indonesia, pemerintah pusat berusaha mengelola wilayah perbatasan dengan baik agar tidak lagi direbut oleh Malaysia, seperti kasus Sipadan dan Ligitan beberapa tahun lalu (Abubakar, 2006). Untuk itu, pemerintah memberikan pengamanan yang cukup ketat dengan menghadirkan TNI dan Polisi yang bertugas menjaga keutuhan dan keamanan Negara Kesatuan Republik Indonesia (NKRI). Pemerintah menyediakan sekolah bagi masyarakat Badau sampai pada tingkat menengah atas (SMA) dengan tujuan untuk menambah jumlah peserta didik yang setingkat SMA dan mencegah pelajar bersekolah di wilayah Malaysia. Selain itu, pemerintah juga menyediakan Puskesmas dan Rumah Sakit Keliling agar memudahkan masyarakat memperoleh pelayanan kesehatan, meskipun pelayanan kesehatan ini belum maksimal karena hanya memiliki tiga dokter umum dan belum memiliki dokter spesialis. Di bidang kelembagaan, pemerintah membangun kantor imigrasi kelas tiga yang berhak mengeluarkan Pas Merah bagi masyarakat Badau.

Usaha pemerintah melengkapi kebutuhan infrastruktur tidak berarti banyak dibandingkan kebutuhan nyata atas berbagai fasilitas dasar. Keadaan ini menyebabkan penduduk Badau cenderung membandingkan kebijakan pemerintah Indonesia dengan pemerintah Malaysia di mana pemerintah Indonesia dikatakan lebih sering lupa kepada bangsanya di perbatasan. Tidak banyak yang dapat dipuji dari kebijakan pemerintah Indonesia di daerah Badau, berbeda dengan apa yang dilakukan oleh pemerintah Malaysia. Kebijakan yang dibuat pemerintah Malaysia untuk masyarakat Lubok Antu telah menarik simpati dan pujian masyarakat Badau pada Malaysia karena kebijakan bersifat pro-rakyat. Pada saat yang sama penduduk Badau jugamengalamiakibat positif dari kebijakan yang dibuat pemerintah Malaysia, yang bahkan menciptakan ketergantungan Badau pada Malaysia. Bagi penduduk Badau, pemerintah Malaysia bagaikan dewa penolong.Banyak fasilitas pemerintah Malaysia yang dinikmati oleh penduduk Badau, seperti fasilitas beasiswa anak sekolah, kesehatan, listrik, bahan bakar, hingga subsidi barang kebutuhan pokok.

Fasilitas yang diberikan pemerintah Malaysia memang lebih baik, dari jalan raya yang berkualitas, jaminan pekerjaan dan gaji yang memadai, sekolah yang dilengkapi asrama, panti untuk lansia hingga rumah sakit yang lengkap fasilitas dan murah. Fasilitas kesehatan ini menjadi pilihan orang Indonesia mengingat Puskesmas yang ada di Badau tidak mampu menangani penyakit yang cukup parah, sementara itu untuk berobat ke Pontianak sangat jauh dan mahal. Selain itu, peralatan yang tersedia di Badau masih sangat minim dan hanya mampu menjalankan operasi kepada pasien pada taraf dasar.

Penanda utama dari perbedaan Malaysia dan Indonesia adalah fasilitas jalan raya.Jalan raya di wilayah Indonesia jauh dari layak dibandingkan tetangga. Banyak lubang di sepanjang jalan utama, padahal jalan ini sangat strategis yang menghubungkan Badau dengan berbagai daerah. Hanya beberapa bagian jalan yang sudah diperbaiki, seperti jalan menuju PLB (Pos Lintas Batas) yang panjangnya tidak lebih dari dua kilometer. Setelah melewati jalan menuju PLB, jalan dari Badau menuju perusahaan sawit lebih rusak lagi. Hanya terlihat sisa-sisa aspal yang sudah berlubang di sana-sini.Ketika perjalanan diteruskan, aspal rusak berlubang sudah berganti dengan jalan tanah. Pada saat yang sama di wilayah Malaysia sulit ditemukan jalan yang berlubang.

Perbedaan kualitas hidup ini menyebabkan hidup berdampingan dengan negara Malaysia tidaklah mudah bagi masyarakat Badau. Mau tidak mau mereka selalu membandingkan fasilitas-fasilitas yang didapatkan "saudara" mereka di seberang dengan apa yang mereka miliki sebagai warga Indonesia. Seringkali mereka merasa iri dengan fasilitas-fasilitas yang diberikan oleh pemerintah Malaysia. Untuk itu, penduduk Badau seringkali mengatakan bahwa menjadi orang Malaysia lebih enak, 
fasilitas terpenuhi, mendapatkan berbagai subsidi dari pemerintah, khususnya subsidi pendidikan, kesehatan, dan barang kebutuhan pokok yang lebih murah (minyak, gula, garam, tepung). Keluh kesah juga sering terdengar dari pegawai negeri sipil, demikian pula anggota TNI dan Polisi, yang sangat sadar bahwa fasilitas yang didapatkan oleh pegawai dan aparat Malaysia di daerah perbatasan mencakup gaji yang memadai dan fasilitas tempat tinggal yang lebih baik.

Pada konteks ini Indonesia direpresentasikan dengan jalan yang buruk, fasilitas kelembagaan yang miskin, dan kehidupan yang masih terbelakang. Sebagai daerah perbatasan, desa Badau menghadapi persoalan ketimpangan, kekurangan, dan kesulitan yang telah berlangsung dalam waktu yang cukup panjang (Abdullah, 2013). Pada saat yang sama, Badau merupakan bagian dari infrastruktur dan kebijakan negara tetangga yang lambat laun menciptakan citra tentang negeri tetangga dan citra dirinya sebagai warga Indonesia yang serba kekurangan. Apalagi, pemerintah Indonesia dinilai hanya hadir dalam bentuk alat-alat negara, seperti polisi, tentara, aparatur desa, lambang negara, dan bendera.

\section{Kontestasi Identitas Majemuk Dayak Iban}

Kehidupan Badau sebagai masyarakat wilayah perbatasan, tidak bisa dilepaskan dari kehidupan masyarakat Malaysia di Lubok Antu, khususnya karena masyarakat asli Badau dan masyarakat asli Lubok Antu bersaudara berasal dari satu etnis: Dayak Iban. Kehidupan mereka terpisah akibat negara telah menarik batas (administratifpolitik) yang tegas, siapa yang menjadi penduduk Indonesia dan siapa yang menjadi penduduk Malaysia ditentukan oleh politik negara. Batas ini bersifat sepihak ketika negara membagi satu satuan kultural etnis menjadi dua bagian tanpa memperhatikan batas-batas kultural-historis suatu etnis (Gambar 3). Mereka pun tidak memiliki pilihan untuk menjadi warga negara karena faktor geografis tempat tinggal telah menjadi penentu absolut atas keberadaan mereka di wilayah Indonesia atau Malaysia. Akan tetapi, perbedaan identitas mereka sebagai warga negara tidak menjadikan mereka terpecah secara kultural-antropologis yang tampak dari adanya ruang kultural bersama yang mereka bangun dan pelihara melalui berbagai ritual dan simbol.

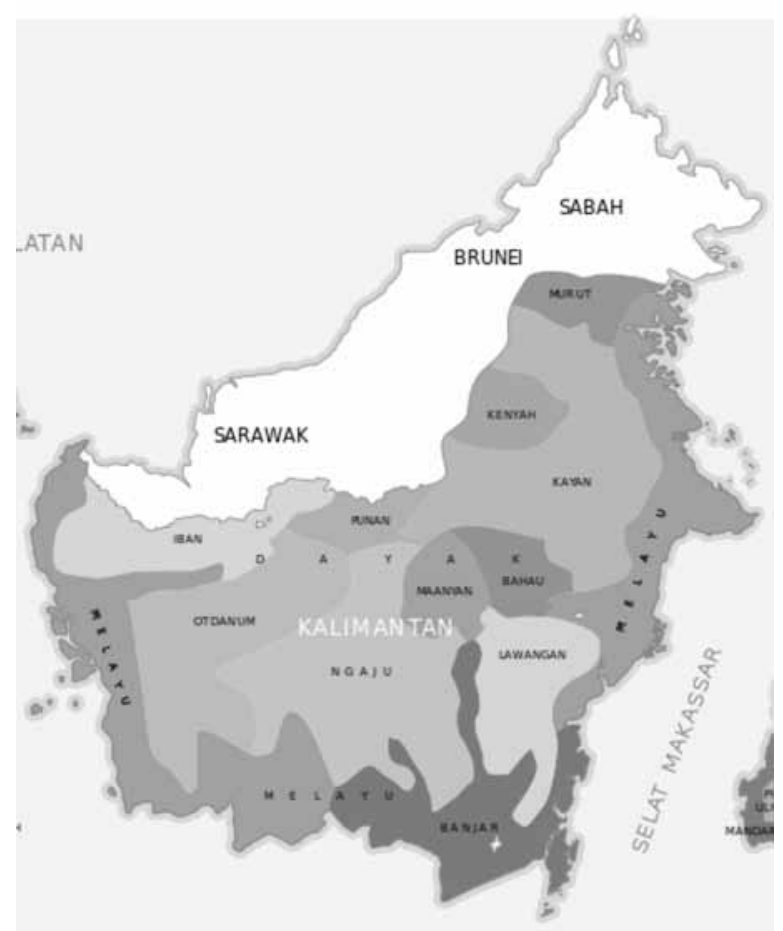

Gambar 3: Peta Etnis Iban di Kalimantan Barat Sumber: www.google.com

Keterikatan penduduk dua Negara dipelihara melalui bahasa (bahasa Dayak Iban), perlengkapan upacara adat, rumah panjang, dan praktik ritual. Apabila ada salah satu keluarga di Badaumelangsungkan pernikahan maka keluarga dari Malaysia sudah dapat dipastikan turut diundang. Dalam kehidupan sehari-hari mereka seperti tidak menghiraukan adanya batas-batas teritorial yang dibuat oleh negara. Kedekatan emosional masyarakat Badau dengan keluarga mereka di Malaysia terus dipelihara, termasuk dengan mencarikan jalan bagi saudara mereka yang berada di wilayah Badau (Indonesia) untuk mendapatkan berbagai fasilitas pemerintah Malaysia, termasuk dengan cara memberi jaminan untuk keluarga mereka dari Indonesia 
dalam mengakses fasilitas kesehatan dan pendidikan. Banyak warga Badau, misalnya, menyekolahkan anak mereka ke Malaysia atas jaminan keluarga yang ada di Malaysia.Malaysia memang membuka kesempatan bagi orang Indonesia untuk bersekolah tetapi dengan syarat memiliki IC (Identity Card) yang dapat diperoleh jika memiliki akte kelahiran Malaysia.Selain atas alasan kewarganegaraan Malaysia, IC juga dapat diperoleh dengan lahir di rumah sakit Malaysia meskipun kedua orangtua adalah Warga Negara Indonesia. Konteks kebijakan Malaysia yang terbuka semacam ini telah mendukung reproduksi budaya Iban dan pada saat yang sama pelestarian hubungan kultural penduduk Badau dengan penduduk Malaysia.

Ketika hubungan kekerabatan menjadi kekuatan bagi penduduk Badau untuk mendapatkan berbagai fasilitas di Malaysia, seperti melalui mekanisme jaminan, maka kekerabatan menjadi penting untuk dipelihara karena tidak hanya bermakna kultural, tetapi juga struktural. Kecenderungan ini mempersulit definisi identitas warga Badau, di antara menjadi warga Indonesia dengan sikap nasionalisme yang teguh dan menjadi bagian dari Malaysia atas tuntutan ekonomi politik-pragmatis. Hubungan yang kompeks semacam ini tampak bahwa warga Badau, setidaknya, memiliki tiga identitas yang secara bergantian mendefinisikan siapa mereka. Pertama, mereka adalah warga negara Indonesia yang hidup dan patuh pada aturan Negara Republik Indonesia, walaupun Negara tidak mampu mencukupi kebutuhan mereka sebagai warga negara. Mereka hidup dengan infrastruktur yang terbatas, jalan yang buruk, sekolah yang serba kekurangan, pusat kesehatan yang kurang baik, hingga harga-harga yang melambung tinggi. Kebutuhan listrik mereka masih dipasok dari daerah Lubok Antu. Barang-barang kebutuhan sehari-hari, mereka dapatkan dari pasar Lubok Antu, bahan bakar minyak ilegal milik Malaysia, kendaraan-kendaraan murah dari Malaysia, sekolah gratis yang dilengkapi asrama, pekerjaan yang menjanjikan upah yang tinggi, hingga biaya kesehatan yang sangat murah. Di tengah-tengah tekanan semacam ini mereka tetap menjadi Indonesia.

Kedua, masyarakat Badau juga dihadapkan pada permasalahan kultural yang menggugat identitas mereka. Selain sebagai bagian dari warga negara Indonesia bersama etnis Melayu, Jawa, Flores, dan etnis-etnis lain, kelompok mayoritas Dayak Iban menjadi bagian dari Dayak Iban Serawak yang menjadi warga Negara Malaysia. Atas latar belakang kultural-etnis ini warga Badau tidak jarang bersikap mendua karena posisi sebagai bagian dari warga Malaysia memungkinkan mereka menikmati sejumlah keuntungan, seperti kesempatan pendidikan bagi anak-anak mereka dan pekerjaan yang lebih baik.Kesatuan emosionalkultural yang berasal dari satu etnis telah menjadi dasar strategis-politis bagi warga Badau, khususnya etnis Dayak Iban, untuk mendapatkan berbagai kemudahan. Masuknya negara dengan membuat garis Negara (state line) yang mengatur batas teritorial disertai aturan-aturan yang harus dipatuhi oleh masing-masing warga negara, maka, masyarakat Dayak Iban kemudian seperti terbelah dua, Dayak Iban milik Indonesia dan milik Malaysia. Negara memang tidak bisa menghapus begitu saja sejarah bahwa mereka adalah satu kesatuan yang berasal dari nenek moyang yang sama yang memiliki ikatan emosional yang kuat.

Ketiga, walaupun terletak jauh dari pusat perkembangan, baik kabupaten maupun provinsi, Badau tetaplah bagian dari masyarakat global.Warga Badau memiliki sifat yang terbuka pada barang-barang baru, orang-orang baru, dan nilai-nilai baru yang masuk ke dalam kehidupan mereka.Barangbarang di Badau tidak terbatas pada barang yang berasal dari Indonesia dan Malaysia, barang-barang dari Cina, Jepang, Korea, juga masuk ke wilayah perbatasan. Pakaian Cina, mobil dan sepeda motor Jepang, perangkat elektronik Korea, atau alat telekomunikasi Taiwan dengan mudah ditemukan di rumahrumah warga Badau. Selain persinggungan 
mereka yang intensif dengan kehidupan material dari luar, warga Badau juga memiliki tingkat mobilitas yang tinggi terkait dengan usaha mereka mendapatkan kehidupan yang lebih baik.Tidak jarang keberadaan mereka di Malaysia menciptakan suatu kesadaran baru tentang masyarakat tanpa batas yang dapat hidup dalam dunia yang bebas lepas dari batas-batas Negara yang mengekang (Govers dan Vermeulen, 1997).Cukup banyak dari penduduk yang terlibat dengan perusahaan perkebunan baik yang dimiliki oleh Indonesia maupun Malaysia.

Identitas Badau merupakan identitas yang dinamis dan kontestatif (Burke dan Stets, 2009).Tidak saja identitas terbangun secara kondisional atas tuntutan-tuntutan nyata yang dihadapi warga Badau, yang mengharuskan mereka responsif dan adaptif, juga sesuatu yang diperjuangkan dan dibela sebagai warga Negara yang mencintai tanah airnya. Semangat bela tanah air ini, terutama atas citra buruk Indonesia di perbatasan, yang telah menegaskan adanya Badau sebagai pintu gerbang untuk masuk ke wilayah Republik Indonesia.

\section{Badau sebagai Ruang Perbatasan Tanpa Batas}

Permasalahan Badau sebagai wilayah perbatasan bukan sekadar ketidakmampuan pemerintah dalam menyediakan barangbarang publik (public goods) bagi warga, tetapi juga menyangkut dinamika lingkungan strategis global yang menempatkan Badau dalam suatu peta ekonomi politik internasional. Badau bukan sekadar wilayah perbatasan yang terpencil di perbatasan dua Negara, tetapi juga sebagai wilayah penghasil kayu, perkebunan subur, dan sumber ikan yang kaya yang telah menarik minat pelaku ekonomi asing. Ketika hutan kayu habis akibat perdagangan dan penebangan liar, lahan di wilayah perbatasan IndonesiaMalaysia ini menjadi kompleks perkebunan karet dan sawit. PT Sinar Mas salah satu perusahan perkebunan yang menjalankan operasi, bahkan akan mendirikan pabrik pengolahan sawit di wilayah ini. Kehadiran perusahaan semacam ini tentu saja akan membuka lapangan kerja yang signifikan dan meningkatkan peredaran uang serta mendorong pertumbuhan ekonomi.

Penduduk Badau memenuhi kebutuhan pekerjaan dengan bekerja di perkebunan yang ada di wilayah Indonesia dan menjadi tenaga kerja perkebunan di wilayah Malaysia. Sebagian juga terlibat sebagai pedagang yang membawa barang-barang ke Malaysia. Bekerja di Malaysia lebih memiliki daya tarik karena penghasilan lebih besar dibandingkan bekerja di negeri sendiri.Dalam satu hari, para buruh bisa mendapatkan upah hingga RM 50 sehingga mereka bisa meraih upah 2.000 RM dalam satu bulan. Dengan nilai tukar RM 1 sama dengan Rp 3.250, maka bekerja di Malaysia akan mendapatkan penghasilan Rp 6.500.000. Jika bekerja sebagai buruh harian di Indonesia, mereka hanya mendapatkan gaji Rp 50.000 perhari atau hanya Rp 1.500 .000 perbulan. Perbedaan jumlah pendapatan yang cukup tinggi inilah yang menjadi daya tarik warga Badau bekerja di Malaysia.

Pemerintah Malaysia membutuhkan tenaga kerja dari Indonesia untuk "pekerjaan kasar" karena Malaysia kekurangan tenaga kerja untuk perkebunan karet dan sawit. Sebagian besar mereka adalah buruh ilegal yang tidak dilengkapi dengan dokumen resmi dan ijin kerja.Warga Negara Indonesia yang bekerja dalam sektor perkebunan di wilayah ini mencapai 2000 orang. Mereka tinggal di dalam perkebunan, yakni di rumah panjang yang sudah disediakan, dalam suatu kehidupan menyerupai desa. Di dalam kebun juga terdapat kampung yang terdiri kurang lebih 60 orang setiap kampung. Perkampungan yang terdapat di dalam perkebunan ini ternyata hampir sama dengan kampung pada umumnya, ada struktur organisasi masyarakat, ada warga yang menempati kampung tersebut, dan ada sumber daya ekonomi yang menjadi penunjang kehidupan buruh perkebunan ini. Di perkampungan buruh ini juga terdapat warung-warung tempat mereka berbelanja memenuhi kehidupan sehari-hari. Status ilegal yang disandang buruh menyebabkan 
mereka jarang keluar dan pergi ke pasar karena takut dikenali dan ditangkap oleh polisi Malaysia. Menurut pengakuan pekerja, Polisi Malaysia maklum dengan keberadaan mereka sebagai buruh ilegal asalkan mereka tidak berbuat yang tidak pantas dan tidak terlibat kriminalitas.

Sejalan dengan ilegalitas ini masih banyak warga Badau yang memilih bekerja di negeri sendiri karena alasan ketenangan. Mereka tidak ingin hidup selalu dalam situasi terancam dengan kehadiran Polisi Malaysia yang kapan saja bisa menangkap mereka.Dengan bekerja di negeri sendiri di Badau, menurut mereka, warga Badau tetap saja dapat berinteraksi dengan warga Malaysia melalui aktivitas berdagang secara legal ke Malaysia.Mereka membeli barang dari Malaysia dan juga menjual barang yang berasal dari Indonesia seperti pakaian adat, berbagai kerajinan, hingga kebutuhan seharihari.Para pedagang ini, seperti banyak warga yang menggeluti profesi lain, yakin bahwa mereka tetap bisa hidup dengan bekerja di negerinya sendiri tanpa harus berada di bawah bayang- bayang kecemasan ilegalitas. Istilah yang sering dikatakan adalah "walau hujan emas di negeri orang lebih baik hujan batu di negeri sendiri" untuk memperlihatkan komitmen moral-politik warga Badau.

Selain dengan warga Badau yang bekerja sebagai pedagang dan buruh ilegal Badau juga terhubungkan dengan negara lain melalui barang-barang yang masuk melalui Lubok Antu Malaysia. Mobil dan sepeda motor yang digunakan warga Badau umumnya berasal dari Malaysia, bahkan jamak sekali terlihat kendaraan dengan plat nomer Malaysia di wilayah Indonesia. Dalam hal ini tampak jelas bahwa Badau merupakan ruang internasional di mana kendaraan asing beroperasi dengan bebas.Barang-barangyang beredar di Badau menegaskan bahwa Badau bukanlah wilayah terasing karena berbagai produk Malaysia, Jepang, atau Cina dapat ditemukan di wilayah ini.Badau menjadi bagian dari suatu jaringan komunikasi global yang sebagaimana dikatakan Featherstone menjadi tanda integrasi masyarakat lokal ke tatanan global (Featherstone, 1991).Badau, dalam bahasa MacLuhan, tidak kurang sebagai global village yang memperlihatkan betapa nilai-nilai yang dipelajari dan diyakini kemudian bukan hanya berasal dari lokalitas di mana seseorang berada, tetapi juga nilainilai dari suatu pusat dunia (Abdullah, 2010).

Masyarakat Badau yang terintegrasi dengan pasar global mengindikasikan bahwa masyarakatnya merupakan masyarakat yang terbuka.Mereka mudah menerima nilai-nilai baru, seperti teknologi baru dan juga orientasi ruang yang berubah.Orientasi ruang juga tampak dari mobilitas penduduk Badau yang cukup tinggi terutama ke Lubok Antu, Malaysia, baik secara legal menggunakan Pas Merah maupun ilegal melalui jalan tikus yang menjadi rahasia umum.Mobilitas lintas budaya ini menyebabkan warga Badau selalu mengetahui dan terlibat dengan perkembangan nasional dan internasional yang sekaligus menciptakan aspirasi-aspirasi yang luas dalam kehidupan mereka seharihari. Selain pertukaran barang dan informasi terjadi secara intensif dan meluas, Badau juga terlibat dalam wacana ekonomi dan politik yang dapat menyebabkan redefinisi identitas mereka sebagai warga Indonesia di perbatasan (Ardhana, 2006; Sari, 2013).

Keberadaan Badau sebagai "desa global" juga terjadi atas posisi Badau sebagai serambi depanIndonesia, yang inisepenuhnya disadari oleh pemerintah Malaysia, yang tampak dari berbagai kebijakan afirmatif pemerintah Malaysia untuk wilayah perbatasan. Dengan cara ini Malaysia membangun citra positif sebagai Negara yang peduli dan pro-rakyat melalui berbagai kebijakan subsidi yang diterapkan di wilayah perbatasan. Pada saat yang sama tindakan Malaysia ini menaruh simpati warga Badau dan sekitarnya yang kemudian tidak jarang menarik minat warga untuk menjadi warga Negara Malaysia, khususnya melalui perkawinan. Badau pun menjadi ruang bersama dalam pergaulan antarbangsa. Selain perkawinan yang terjadi dengan penduduk Malaysia, Badau menjadi ruang ekonomi di mana banyak orang dari berbagai tempat mencari penghidupan. 
Perlu suatu kesadaran untuk melihat bahwa Badau bukanlah suatu wilayah yang terletak di pinggiran, melainkan di satu titik pusat global yang tampak dalam wacana perbatasan yang menempatkan wilayah Badau sebagai pusat pembicaraan.Badau pun menjadi pusat perhatian ketika kedaulatan Negara dibicarakan karena keberadaan Badau merupakan suatu tanda dari kehadiran atau ketidakhadiran Negara dalam suatu ruang geografis-politik.Badau pun menjadi ruang yang dipertaruhkan secara global karena kedaulatan bukan hanya menyangkut hubungan dua bangsa, tetapi meliputi bangsa-bangsa dunia yang memiliki kepentingan ekonomi politik atas suatu ruang yang keberadaannya diatur dalam suatu konvensi internasional.

\section{SIMPULAN}

Masyarakat Badau sebagai masyarakat perbatasan Indonesia-Malaysia, memposisikan dirinya dalam tiga format identitas, yaitu: identitas sebagai masyarakat perbatasan, identitas sebagai bagian dari masyarakat Iban, dan identitas sebagai bagian dari masyarakat global. Konstruksi identitas ini sejalan dengan yang dikatakan oleh Foote (1951) bahwa identitas individu dibentuk oleh struktur yang mendefinisikannya dan memberi kerangka atas simbol-simbol yang membedakan satu dengan yang lain. Struktur ini kemudian ditegaskan oleh Burke bahwa identitas diri manusia tidak dapat dipandang sebatas siapa dia, tetapi hanya dapat dijelaskan melalui relasi-relasi sosial yang berada di sekitarnya.

Ketiga format identitas ini dipakai bergantian sesuai dengan kebutuhan mereka dan tidak dapat dipakai secara bersamaan karena masing-masing merupakan respons terhadap konteks dan kepentingan yang berlainan. Pertama, identitas sebagai warga perbatasan digunakan untuk memposisikan diri mereka sebagai bagian dari masyarakat Indonesia.Identitas ini biasanya dipakai dalam urusan-urusan formal saja. Kedua, identitas sebagai warga Dayak Iban, dipakai dalam kehidupan sehari-hari yang sangat membantu mereka untuk mendapatkan berbagai fasilitas negara Malaysia yang diberikan melalui saudara mereka di Lubok Antu Serawak, Malaysia.Ikatan kekerabatan ini dipelihara dengan baik karena masyarakat Badau sangat bergantung pada saudaranya yang berada di Malaysia. Ketiga, sebenarnya tidak dipakai secara sengaja karena pasarlah yang memberikan mereka posisi sebagai bagian dari konsumen global yang tidak bisa memisahkan diri mereka dengan apa yang terjadi secara global. Dari situ terbentuk perilaku masyarakat yang terbuka yang ditandai dengan mobilitas penduduk dan mobilitas pekerjaan yang cukup tinggi.

Ketergantungan masyarakat Badau terhadap Malaysia, sejalan dengan kebijakan afirmatif pemerintah Malaysia, telah memperlemah posisi pemerintah Indonesia di mata masyarakat Badau.Mereka merasa bahwa pemerintah Malaysia memiliki kepedulian yang lebih dibandingkan pemerintahnya sendiri. Penduduk Indonesia, khususnya warga Badau, menjadi sangat tergantung pada pasar Lubok Antu, Serawak, karena perekonomian di Lubok Antu telah berkembang menjadi pusat perbelanjaan di mana dengan perjalan setengah jam saja warga Indonesia sudah dapat memenuhi hampir seluruh kebutuhan hidup. Tidak ada pusat perekonomian yang setara di wilayah Indonesia yang dapat dijangkau oleh warga Badau dalam waktu singkat dan dengan jarak yang dekat. Pusat perekonomian terdekat adalah ibu kota kabupaten Kapuas Hulu, Putussibau, yang harus ditempuh lima jam jalan darat dengan keadaan jalan yang buruk. Ketergantungan pada pasar dan barang Malaysia merupakan fakta objektif yang menjadi dasar bagi redefinisi identitas warga yang seringkali menggugat nasionalisme mereka sebagai "orang Indonesia".

Perubahan kehidupan warga perbatasan di Badau hanya dapat dilakukan oleh komitmen dan keterlibatan Negara yanglebih besar melalui kebijakan-kebijakan afirmatif. Permasalahan di wilayah perbatasan harus dipandang sebagai persoalan darurat, bukan kewajiban rutin pemerintah yang harus 
diselesaikan dengan program dan anggaran rutin, sehingga membutuhkan kebijakan tanggap darurat atas ancaman-ancaman yang serius menyangkut identitas warga dan ketergantungan warga pada Negara asing. Pada saat yang sama kedaulatan Indonesia dipertanyakan setiap hari melalui berbagai tanda representasi Negara yang kurang menguntungkan. Negara hanya hadir melalui bendera, aparat, dan peraturan yang kurang pupoler; tidak hadir dalam bentuk jalan yang berkualitas, bantuan kebutuhan pokok, pendidikan yang memadai, dan kesehatan yang layak.

Keseluruhan perubahan ini akan terjadi hanya jika perspektif tentang wilayah perbatasan mengalami pergeseran: bukan sekedar pemisah dua Negara yang tegas secara politik-administratif, tetapi harus dipandang sebagai pintu gerbang yang menjadi cermin bagi wajah Indonesia yang sesungguhnya. Kehidupan yang maju di wilayah perbatasan merupakan tuntutan yang niscaya dalam menegakkan kedaulatan melalui dukungan publik yang nasionalis dan melalui citra sebagai negeri yang makmur dan mandiri melalui kebijakankebijakan yang pro-rakyat dan tindakan afirmatif. Keberadaan institusi pengelolaan perbatasan pun tidak akan berarti banyak jika paradigma pembangunan daerah perbatasan belum bergeser ke cara pandang yang menempatkan perbatasan sebagai titik pusat dari wacana ekonomi politik global atas perebutan sumberdaya ekonomi wilayah perbatasan sekaligus perebutan kedaulatan politik negara-bangsa.

\section{DAFTAR PUSTAKA}

Abdullah, Irwan. 2007. Konstruksi dan Reproduksi Kebudayaan. Yogyakarta: Pustaka Pelajar.

2010. “Model Kultural Pembangunan Daerah Perbatasan:Mengedepankan yang di Pinggir (kan)", Makalah pada Roundtable Discussion Pembangunan Daerah Perbatasan". Jakarta: Lembaga Ketahanan Nasional RI, 29 November.
2013. “Daerah Perbatasan: Misrepresentasi Pembangunan dari Belakang", dalam Irwan Abdullah (ed.), Badau Pasti Berlalu: Catatan Perjalanan dari Wilayah Perbatasan Kalimantan Barat. Yogyakarta: TICI Publications.

Abubakar, Mustafa. 2006. Menata Pulau-pulau Kecil Perbatasan: Belajar dari Kasus Sipadan, Ligitan dan Sebatik. Jakarta: Kompas.

Ardhana, I Ketut. 2006. Dinamika Etnisitas dan Hubungan Ekonomi pada Wilayah Perbatasan di Kalimantan Timur-Sabah: Studi Kasus di Wilayah Krayan dan Long Pasia. Jakarta: Pusat Penelitian Sumber Daya Regional Lembaga Ilmu Pengetahuan Indonesia.

Burke, Peter (ed.). 2001. Advances in Identity Theory and Research. New York: Kluwer Academic.

Burke, Peter dan Jane E. Stets. 2009. Identity Theory. New York: Oxford University Press.

Cramb, R.A. 2007. Land and the Longhouse: Agrarian Transformations in the World of Serawak.Copenhagen : NIAS.

Ehler, Eckart dan Carl Gethmann. 2003. Environment Across Cultures. Berlin: Springlerr Verlag.

Foote, Nelson. 1951. "Identification as the Basis for a Theory of Motivation", American Sociological Review 26:14-21.

Gleditsch, Nielstetter. 1996. "Conflict and the Environment", Environment, Vol. 33, No.1.

Govers, Cora dan Hans Vermeulen. 1997. The Politics of Ethnic Consciousness. New York: McMillan Press.

Harris, Marvin. 1997. Culture, People, Nature. Boston: Addison Wesley Publishing Company Incorporated.

Marsetio. 2009. “Pendayagunaan Wilayah Perbatasan dan Pulau-pulau Terluar Guna Mendukung Pembangunan Nasional Dalam Rangka Persatuan 
dan Kesatuan Bangsa", Makalah, Seminar Pasis Dikreg XXXVI Sesko TNI, 9 Juli, Jakarta.

McCall, George dan J. Simmons. 1978. Identities and Interactions. New York: Free Press.

Meltzer, B.N., J. Petras, L. Reynolds. 1977. Symbolic Interactionism: Genesis, Varieties and Criticism. Boston: Routledge and Kegan Paul.

Prasojo, Zaenuddin Hudi. 2013. "Badauku Sayang Badauku Malang: Dinamika DaerahPerbatasanKalimantan BaratSerawak", dalam Irwan Abdullah (ed.), Badau Pasti Berlalu: Catatan Perjalanan dari Wilayah Perbatasan Kalimantan Barat. Yogyakarta: TICI Publications.

Safitri, Ririh Megah. 2013. “Fungsi dan Disfungsi Negara di Perbatasan: Potret Kehidupan di Badau, KabupatenKapuasHulu, Kalimantan Barat", dalam Irwan Abdullah (ed.), Badau Pasti Berlalu: Catatan Perjalanan dari Wilayah Perbatasan Kalimantan Barat. Yogyakarta: TICI Publications.
Sari, Intan Permata. 2013. "Sulitnya Menjadi Indonesia: Dilema Identitas Komunitas Perbatasan Badau, Kalimantan Barat", dalam Irwan Abdullah (ed.), Badau Pasti Berlalu: Catatan Perjalanan dari Wilayah Perbatasan Kalimantan Barat. Yogyakarta: TICI Publications.

Stone, G. 1962. "Appearance and the Self", dalam A. Rose (ed.), Human Behavior and Social Processes. Boston: Houghton Mifflin.

Stryker, Sheldon. 1987. "Identity Theory: Developments and Extensions", dalam K. Yardley dan T. Honess, Self and Identity. Chichester, UK: Wiley.

Tirtosudarmo, Riwanto. 2005. "Wilayah Perbatasan dan Tantangan Abad 21: Sebuah Pengantar", dalam Riwanto Tirtosudarmo, dkk. Dari Entikong sampai Nunukan: Dinamika Daerah Perbatasan Kalimantan Malaysia Timur (Serawak-Sabah). Jakarta: Pustaka Sinar Harapan. 